\title{
Die direkte Detektion der Pepsinogen- und Pepsin-Fraktionen nach der Agar-Gel-Elektrophorese mit denaturiertem Substrat
}

\author{
Von J. Kamarýt und V. Mechlová \\ Aus dem Forschungsinstitut für Pädiatrie (Direktor: Prof. MUDr. Z. Brunecký, C. Sc.), Brno (ČSSR)
}

(Eingegangen am 21. Juli 1970)

\begin{abstract}
Es wird eine Methode der Fraktionierung von Pepsinogen und Pepsin auf Agar-Gel beschrieben. Die Enzym-Aktivitäten werden mit hitzedenaturiertem Substrat, welches durch die „Sandwich“-Technik zugeführt wird, nachgewiesen. Dic Enzym-Aktivitäten der einzelnen Pepsinogen- oder Pepsin-Fraktionen sind schon während der Inkubation als helle Streifen auf dem trüben Hintergrund sichtbar. Als Beispiele werden die Fraktionierung des Pepsins aus dem Magensaft und des Pepsinogens aus Magenschleimhaut-Extrakt angeführt.

Die Vereinfachung dieser Technik besteht darin, daß die Darstellung der Enzym-Aktivitäten schon während der Inkubationszeit ohne Färbung beobachtet werden kann.
\end{abstract}

\section{The direct detection of pepsinogen and pepsin fractions in agar electrophoresis gels, using denatured substrate}

A method is described for the fractionation of pepsinogen and pepsin on agar gel. The sites of enzyme activity are located with heatdenatured substrate, which is introduced by the "sandwich" technique. The enzyme activities of the individual pepsinogen or pepsin fractions become visible during the course of the incubation as light bands on the turbid backgtound. The method is illustrated by the fractionation of pepsin from gastric juice and of pepsinogen from extracts of gastric mucosa.

The method is simple in that the bands of enzyme activity become visible during the incubation without the use of colour reagents.

Die Feststellung, daß kristallines Pepsin aus Schweinemagen mehr als eine aktive Komponente enthält, geht schon aus der 1940 veröffentlichten Arbeit von HERrIOTT und Mitarbeitern hervor (1). Weitere Berichte darüber haben TAYLOR (2), RYLE und Mitarbeiter (3), URIEL (4) und andere Autoren hinzugefügt.

Die Einführung selektiver analytischer Methoden, wie z. B. der Säulenchromatographie an Ionenaustauschern und der Elektrophorese an verschiedenen Trägern erbrachte weitere Beweise für die heterogene Struktur des aus der menschlichen oder tierischen Magenschleimhaut extrahierten Pepsinogens. TANG und TANg (5) isolierten durch Chromatographie an DEAE-Cellulose zwei Pepsinogene, SEIJfFers und Mitarbeiter $(6,7,8)$ gewannen drei Pepsinogene aus Magenschleimhaut-Extrakt. Durch Agar-Gel-Elektrophorese des gleichen Materials haben KUSHNER und Mitarbeiter (9) und weiter HrRSCH-MARIE $(10,11)$ vier Pepsinogene identifiziert, welche sie nach abnehmender elektrophoretischer Beweglichkeit P I bis IV bezeichnet haben. HANLEY und Mitarbeiter (12) differenzierten durch Stärke-Gel-Elektrophorese drei Pepsinogene, wovon P II und P III eine Verdoppelung aufwiesen. Mit der Agar-Gel-Elektrophorese gewannen SAMLOFF und Mitarbeiter (13) im MagenschleimhautExtrakt acht scharf getrennte Fraktionen. Die Diskrepanz in der Zahl der von verschiedenen Autoren gefundenen Pepsinogen-Fraktionen hängt also von der benutzten Technik ab. Die Autoren sind sich aber darüber einig, daß die Pepsinogen-Heterogenität der Fundus-Magenschleimhaut wesentlich bunter als die der Pylorus-Magenschleimhaut ist.

Wurde zur Pepsinogen-Separation die elektrophoretische Technik benutzt, exfolgte die Detektion der Enzym-
Aktivitäten durch Eintauchen des feuchten Elektropherogramms in die stark saure Protein-Lösung (Albumin, Fibrin, Eier-Eiweiß, Casein oder Hämoglobin). In das Elektropherogramm diffundiertes Protein wird an Stellen, wo die Isoenzyme in der Agar-Gel-Schicht nach der Elektrophorese lokalisiert sind, durch Wirkung des sauren Milieus und Konversion der Pepsinogene in Pepsin gespalten, so $\mathrm{da} B$ nach Fixierung, Trocknen und Färbung mit Amidoschwarz 10B, die Fraktionen der proteolytischen Aktivitäten als helle Zonen auf dem dunkelblauen Hintergrund sichtbar werden.

In diesem rein methodischen Beitrag legen wir unsere Erfahrungen mit der Fraktionierung von Pepsin und Pepsinogen durch Agar-Gel-Elektrophorese vor. Wir benutzten für die Detektion der Enzym-Aktivität denaturiertes Substrat, welches durch die „Sandwich"Technik mit dem Enzym in Kontakt gebracht wurde. Wir waren bestrebt, mit dieser Technik die Verfolgung der Enzym-Reaktion bereits im Laufe der Inkubation möglich zu machen. Diese Technik stellt überdies eine generelle Vereinfachung des Detektions-Vorganges von Protease-Aktivitäten dar.

\section{Material}

Pepsin wurde im Magensaft, Pcpsinogen im Urin und wäßr. Extrakten von Magenschlcimhaut, welche aus dem menschlichen Material (nicht später als $24 \mathrm{Stdn}$. nach dem Tode) gewonnen wurde, bestimmt ${ }^{1}$ ).

1) Für das überlassene Material danken wir Herrn Dr. B. Habanec, II. Institut für Pathologische Anatomie des Universitätskinderkrankenhauses Brno. 


\section{Methodik und Ergebnisse}

Für die elektrophoretische Fraktionierung in 1,2proz. Agar-Gel haben wir Puffer von pH 5, 6 und 7 benutzt. Am besten hat sich Phosphat-Puffer pH $6(\mu=0,05)$ bewährt, weil bei diesen Bedingungen die Fraktionierung nicht nur des Pepsinogens, sondern auch des Pepsins möglich ist. Wie bekannt ist, verliert im sauren Milieu zu Pepsin aktiviertes Pepsinogen durch nachfolgende Neutralisierung oder Alkalisierung seine ursprüngliche Aktivität völlig.

Die Elektrophorese führen wir auf Objektträgern $(26 \times 76 \mathrm{~mm}, 3 \mathrm{~m} / 1,2$ proz. Agar) durch. Der Start in Form einer kleinen Rille von $16 \times 1 \mathrm{~mm}$ befindet sich $19 \mathrm{~mm}$ von dem kathodischen Rand des Agar-GelPlättchens entfernt. Das Auftragen der ana partes mit 2proz. Agar in Puffer $(\mu=0,1 ; \mathrm{pH}$ 6) verdünnten Probe nehmen wir bei einer Temperatur von $44^{\circ}$ vor.

Die stark sauren Magensaftproben müssen etwa eine Stunde gegen Elektrophorese-Puffer dialysiert werden. Für die Aktivierung des Pepsinogens zu Pepsin im sauren Milieu hat sich uns die Dialyse gegen 0,1N Salzsäure mit nachfolgender Dialyse gegen den Puffer, welcher zur Elektrophorese benutzt wurde, bewährt. Dieses Vorgehen bietet eine gute Trennung ohne Krümmung der Fraktionen. Die Elektrophorese dauert 80 Minuten bei $30-35 \mathrm{~V}$ und $5-6 \mathrm{~mA}$ pro AgarSchicht.

Die Detektion der Enzym-Aktivitäten wird mit dem hitzedenaturierten Substrat durchgeführt. Als Substrat wurde entweder eine Lösung von Human-Trockenplasma oder Eialbumin benutzt. Im ersten Fall wird Trockenplasma aus $150 \mathrm{~m} /$ Plasma nur mit $100 \mathrm{~m} /$ destilliertem Wasser gelöst. Zu $40 \mathrm{ml}$ des warmen flüssigen 1,2proz. Agar fügt man nach Abkühlen auf etwa $60^{\circ} 6 \mathrm{ml}$ der Plasma-Protein-Lösung. Nach Einmischen wird diese Lösung auf dem Wasserbad erwärmt, bis das Plasma-Protein zu denaturieren beginnt und eine dichte Trübung, aber keinen Niederschlag oder Flocken bildet.

Genauso verfährt man bei der Vorbereitung der AgarGel-Detektionsschicht mit Eialbumin, nur daß 10proz. Eialbumin-Substrat in 0,9proz. $\mathrm{NaCl}$-Lösung hergestellt wird.

Dann wird die Agar-Substrat-Lösung durch ein dichtes Nylonfilter filtriert und je $3 \mathrm{ml}$ auf Objektträger pipettiert. Nachdem das Agar-Gel erstarrt ist, werden die Plättchen für 15 Minuten in 0,1 N Salzsäure eingetaucht. Diese Zeit reicht aus, um den optimalen $\mathrm{pH}$-Wert in der Agar-Gel-Schicht nicht nur für die Konversion des Pepsinogens zu Pepsin, sondern auch für die mit Pepsin katalysierte enzymatische Reaktion zu erreichen. Anders ist es nicht möglich, dieses stark saure Milieu im AgarGel einzustellen, weil stark saure flüssige Agar-Lösung nach Abkühlen nicht mehr erstarrt. Salzsäure-Überschuß wird mit Filterpapier-Streifen abgesaugt und.die so vorbereitete Detektionsschicht nach der Elektrophorese auf die Elektrophoreseschicht gelegt. Die so entstehenden „Sandwiches“ werden feuchtem Milieu bei $37^{\circ}$ ausgesetzt. Schon während der Inkubationsperiode kann man dort, wo die Fraktionen mit proteolytischer Aktivität lokalisiert sind, helle Zonen beobachten. DieInkubationszeit kann man entsprechend der Aktivitäts-Darstellung wählen. Stoppen der enzymatischen Reaktion ist nicht notwendig, ist aber durch Eintauchen des „Sandwiches" in 5proz. Trichlorressigsäure möglich. Die Dokumentation der noch feụchten Enzymelektropherogramme kann man durch Projizieren auf Photopapier durchführen. Für die direkte Densitometrie ,in situ" hat sich uns der nahe UV-Bereich (366-400 nm) bewährt. Es gibt aber auch die Möglichkeit, die auf Photopapier projizierten Enzymelektropherogramme im Auflicht densitometrisch auszuwerten.

Abbildung 1 stellt die Elektropherogramme des Magensaft-Pepsins, welches mit Puffer pH $\sigma$ bei steigenden Laufzeiten fraktioniert wurde, dar:Die zweite Abbildung zeigt die Elektrophorese des Pepsins und Pepsinogens aus der Magenschleimhaut des Fundus und Pylorus. Aus der Abbildung geht das Vorkommen der 3 bis 4 Pepsinogen-Fraktionen im Fundus-Extrakt hervor. Nach vorherigem Ansäuern desselben Materials kann man nicht nur eine Beschleunigung der elektrophoretischen Beweglichkeit, sondern auch die Reduktion der Anzahl der Pepsin-Fraktionen beobachten. Was das PepsinogenZymogramm der Pylorus-Schleimhaut betrifft, ist diese Heterogenität nicht so kompliziert, was auch in guter Übereinstimmung mit den Befunden anderer Autoren ist.

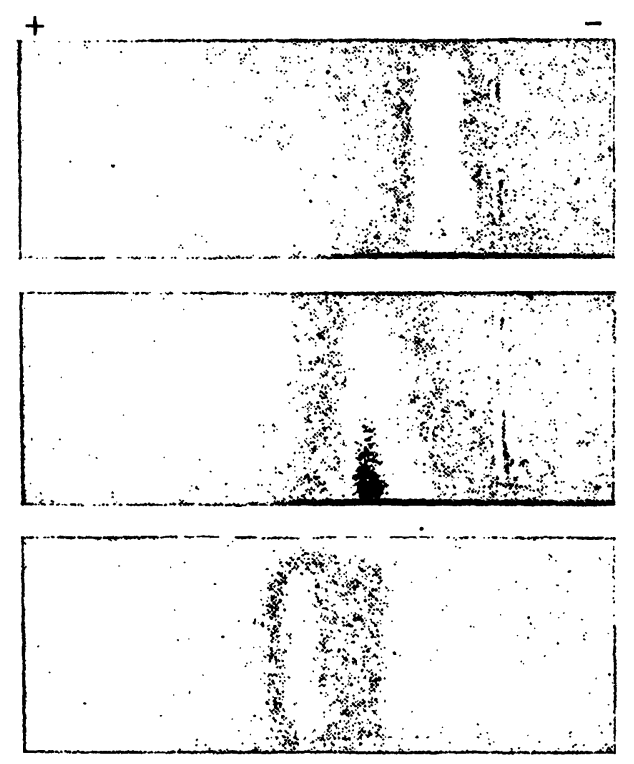

Laufzeit in Minuten

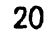

40

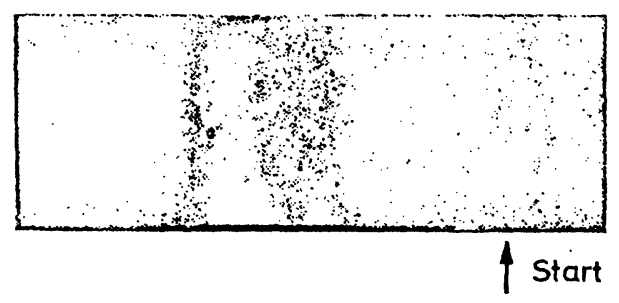

Abb. 1 Agar-Gel-Elektrophorese von Magensaft-Pepsins nach 20, 40, 60 und
80 Min. Laufzeit. Elektrophorese: Phosphatpuffer $\mathrm{pH} 6, \mu=0,05$; 5-6 mA pro Schicht, 4-5 V/cm. Für die Detektion der PepsinAktivitäten wurde Plasmaprotein als Substrat benutzt; Inkubationszeit $60 \mathrm{Min}$. Die Abbildungen wurden durch Projizieren der Enzymelektropherogramme auf Photopapier hergestellt 
Abbildung 3 stellt einen Vergleich derselben Proben, in welchen die Enzym-Aktivitäten entweder mit Blutplasma oder Eialbumin dargestellt wurden, vor.

\section{Diskussion}

Die beschriebene Detektions-Technik zur Pepsinogenund Pepsin-Fraktionen-Bestimmung stellt cine Vereinfachung dieses Vorganges dar. Als sehr vorteilhaft sehen wir die Möglichkeit der direkten Beobachtung der Darstellung von Enzym-Aktivitäten schon im Laufe der Inkubations-Periode an.

Die beschleunigte elektrophoretische Beweglichkeit der proteolytisch aktiven Fraktionen erfolgt auf Grund des Verlustes der basischen Peptide, welche bei der Konversion des Pepsinogens in Pepsin vorkommen. Im Vergleich mit den Befunden von SamLoff (13) haben wir eine niedrigere $Z$ ahl von Pepsinogenen gefunden. Wir müssen aber berücksichtigen, daß der erwähnte Autor die Elektrophorese auf $20 \mathrm{~cm}$ langen Platten bei einer Laufzeit von 3 Stunden durchführt. Beachtenswert ist, $\mathrm{da} B$ er nur die Migrations-Beschleunigung nach vorherigem Ansäueren beschrieb, nicht aber die Reduktion der Anzahl der Fraktionen. Der Befund der ungleichen Zahl von Pepsinogenen in Magenschleimhaut des Fundus im untersuchten biologischen Material deutet auf genetisch bedingtes Vorkommen der einzelnen Fraktionen. Die ursprünglichen Vorschläge von HaNLEY und Mitarbeitern, daß im Falle der Pepsinogen-Heterogenität die Bildung aller Fraktionen einem einzigen Gen untergeordnet ist und die Differenzierung durch Modifikation des Produktes dieses einzigen Genes erst später erfolgt, sind unseres Erachtens nicht berechtigt. Es gilt vielmehr als wahrscheinlich, daß die Bildung jedes Pepsinogens unter der Kontrolle eines selbständigen Genes steht. Dies wird auch mit der Arbeit von SAMLofF und Mitarbeitern (13) bestätigt, wo in allen MagenschleimhautExtrakten nicht dieselben Pepsinogen-Fraktionen identifiziert wurden. Den letzten Beweis dafür stellt die neuere Arbeit von SAMLOFF und Mitarbeitern (14) dar, welche den genetischen Polymorphismus des Pepsinogens bereits bespricht. Die Verwendung dieser Bestimmung für genetische Ziele hat auch uns zu dieser methodischen Studie geführt.

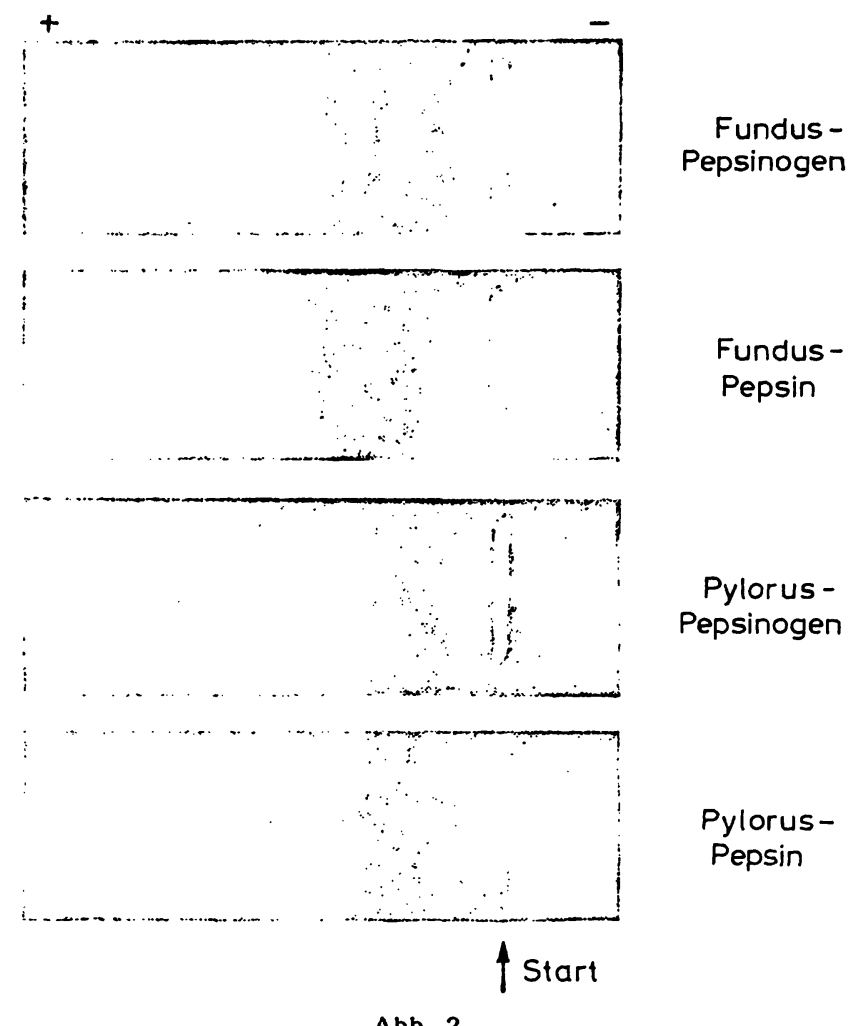

Abb. 2

Fraktionierung des Pepsinogens und Pepsins aus dem Magenschleim haut-Extrakt des Fundus und Pylorus. Für die Detektion der Enzym-Aktivitäten wurde Plasmaprotein als Substrat benutzt; Inkubationszeit $80 \mathrm{Min}$. Weitere Angaben im Text

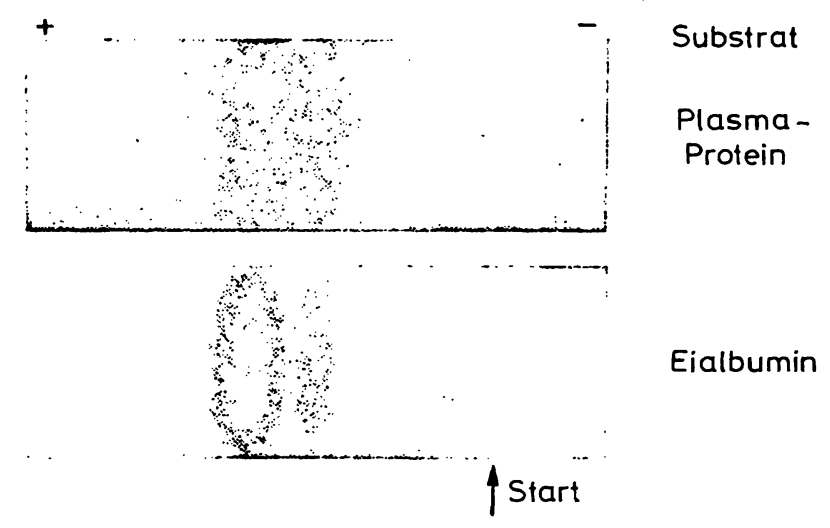

Abb. 3 Pepsin-Fraktionierung des Magensaftes. Die Enzymaktivitäten
wurden mit dem Plasmaprotein und mit Eialbumin als Substrat dargestellt; Inkubationszeit $60 \mathrm{Min}$.

\section{Literatur}

1. Herriott, R. M., V. Desreux und I. H. Northrop, J. Gen. Physiol. 24, 213 (1940). - 2. TAYLOR W. H., Biochem. J. 71, 384 (1959). - 3. RYle, A. P. und R. R. Porter, Biochem. J. 73, 75 (1959). - 4. URIEL, J., Nature London, 188, 853 (1960). 5. TANG, J., und K. I. TANG, J. biol. Chemistry 238, 606 (1963). 6. Seijffers, M. J., H. L. Segal und L. L. Miller, Amer. J. Physiol. 205, 1099 (1963). - 7. SeIjFfers, M. J., H. L. SEGAL und L. L. Miller, Amer. J. Physiol. 205, 1106 (1963). - 8. Seijffers, M. J., L. L. Miller und H. L. Segal, Biochemistry USA 3, 1
(1964). - 9. Kushiner I., W. Rapp und P. Burtin, J. Clin. Invest. 43, 1983 (1964). - 10. Hirsch-Marie, H., Biol. Gastro-Entérologie 2, 109 (1968). - 11. Hirsch-Marie, H., und M. Conte, Rev. frç. Etud. Clin. Biol. 14, 977 (1969). - 12. Hanley, W. B., H. Boyer und M. A. Naughton, Nature London 209, 996 (1966). 13. SAMLOFF, I. M., Gastroenterology Baltimore 57, 659 (1969). 14. SAmLoff, I. M., und P. L. Townes, Science Washington 168 , 144 (1970). 